\title{
Connexin43 enhances the expression of osteoarthritis-associated genes in synovial fibroblasts in culture
}

\author{
Aditi Gupta ${ }^{\dagger}$, Corinne Niger ${ }^{\dagger}$, Atum M Buo, Eric R Eidelman, Richard J Chen and Joseph P Stains ${ }^{*}$
}

\begin{abstract}
Background: Recent work has shown that the gap junction protein connexin43 (Cx43) is upregulated in cells of the joint during osteoarthritis (OA). Here we examined if the OA-associated increase in Cx43 expression impacts the function of synovial fibroblasts by contributing to the production of catabolic and inflammatory factors that exacerbate joint destruction in arthritic disease.

Methods: Using rabbit and human synovial fibroblast cell lines, we examined the effects of Cx43 overexpression and Cx43 siRNA-mediated knockdown on the gene expression of OA-associated matrix metalloproteinases (MMP1 and MMP13), aggrecanases (ADAMTS4 and ADAMTS5), and inflammatory factors (IL 1, IL6 and PTGS2) by quantitative real time RT-PCR. We examined collagenase activity in conditioned media of cultured synovial cells following Cx43 overexpression. Lastly, we assessed the interplay between Cx43 and the NFKB cascade by western blotting and gene expression studies.

Results: Increasing CX43 expression enhanced the gene expression of MMP1, MMP13, ADAMTS4, ADAMTS5, IL1, IL6 and PTGS2 and increased the secretion of collagenases into conditioned media of cultured synovial fibroblasts. Conversely, knockdown of Cx43 decreased expression of many of these catabolic and inflammatory genes. Modulation of Cx43 expression altered the phosphorylation of the NFKB subunit, p65, and inhibition of NFkB with chemical inhibitors blocked the effects of increased Cx43 expression on the mRNA levels of a subset of these catabolic and inflammatory genes.

Conclusions: Increasing or decreasing Cx43 expression alone was sufficient to alter the levels of catabolic and inflammatory genes expressed by synovial cells. The NFKB cascade mediated the effect of Cx43 on the expression of a subset of these OA-associated genes. As such, Cx43 may be involved in joint pathology during OA, and targeting Cx43 expression or function may be a viable therapeutic strategy to attenuate the catabolic and inflammatory environment of the joint during $O A$.
\end{abstract}

Keywords: Synovial fibroblasts, Connexin, Gap junction, Signal transduction, NFkB, RelA, Osteoarthritis, Cytokines

\section{Background}

OA is a progressive degenerative joint disease caused by wear and tear on the articular surface. $\mathrm{OA}$ is thought to be a total joint disease, involving contribution from the articular chondrocytes, sub-chondral bone and synovium [1]. Articular chondrocytes are responsible for producing and maintaining the articular cartilage extracellular matrix

\footnotetext{
* Correspondence: jstai002@umaryland.edu

${ }^{\dagger}$ Equal contributors

Department of Orthopaedics, University of Maryland School of Medicine, 100 Penn Street, Allied Health Building, Room 540E, Baltimore, MD 21201, USA
}

that provides a smooth surface for low friction joint movement and "shock absorbing" properties. The synovial cells form a thin lining within the fibrous joint capsule surrounding the joint space. The synovium is composed of synovial fibroblasts and synovial macrophages. The physiologic function of the synovial fibroblasts is to produce a synovial fluid rich in hyaluronan and superficial zone protein/lubricin that lubricates the joint to facilitate low friction movement. While the etiology of OA is complex, biomechanical and biological factors, such as mechanical strain and inflammatory cytokines 
alter the homeostatic balance between anabolic and catabolic factors in the joint, ultimately leading to the destruction of the articular cartilage. Specifically, synovial cells and articular chondrocytes produce catabolic factors, such as matrix metalloproteinases (e.g., MMP-1 and -13), aggrecanases (e.g., ADAMTS-4 and -5), and pro-inflammatory factors/cytokines (e.g., IL-1, IL-6, $\mathrm{TNF} \alpha$, nitric oxide, prostaglandin $\left.\mathrm{E} 2\left(\mathrm{PGE}_{2}\right)\right)$ that contribute to joint destruction in OA [2-5]. Ultimately, the destruction of articular cartilage can affect joint mobility, leading to severe joint stiffness and pain. Determining the precise contribution and the dynamic interplay between the joint tissue during disease onset and progression is critical to understanding OA and for developing interventions.

One means by which cells and tissues coordinate function is via cell-to-cell communication through gap junction proteins. Gap junctions are made up of connexin monomers that assemble to form a hemichannel. Gap junctions are formed when hemichannels on the plasma membrane of adjacent cells dock to create a transcellular channel. The resultant gap junction channel permits the direct exchange of second messengers, metabolites, ions and other small molecules $(<1.0 \mathrm{kDa})$ among coupled cells. Gap junctions aggregate into large gap junction plaques at the interface of adjacent cells, forming a functional syncytium for the coordinated function of a tissue. Notably, the majority of cells in the joint express the gap junction protein $\mathrm{Cx} 43$, including synovial fibroblasts, articular chondrocytes and osteoblasts, as well as cells of the meniscus and ligaments [6-13]. In fact, intercellular gap junctional communication has been demonstrated among chondrocytes of the superficial layer of articular cartilage in vivo [14]. Ex vivo chondrocytes in cartilage explants have been shown to form functional gap junction networks [15].

In addition to its role in direct gap junctional communication, Cx43 can also form hemichannels that communicate signals directly to the extracellular space $[16,17]$. In the cells of bone and cartilage, hemichannels have been implicated in signaling mechanical load responses $[18,19]$ and are thought to function by serving as conduits for the release of ATP or $\mathrm{PGE}_{2}$ into the extracellular milieu following mechanical strain [20]. Regardless of the mode of action (hemichannel or gap junction channel), the relative expression of $\mathrm{Cx} 43$ alone impacts signal transduction cascades, gene expression and cell function, at least in bone cells [21].

Several lines of evidence indicate a role for $\mathrm{Cx} 43$ in OA. Synovial biopsies from patients with OA have an increase in Cx43 expression and an increase in the size and number of gap junction plaques [22]. Furthermore, ex vivo analysis of synovial biopsies of patients with $\mathrm{OA}$ revealed that pharmacologic inhibition of $\mathrm{Cx} 43$ function reduced the basal and IL- $1 \beta$-stimulated production of collagenase activity $[22,23]$. We have shown that treatment of HIG82 rabbit synoviocytes in culture with IL-1 $\beta$, a contributor to OA, markedly increases the expression of Cx43 and increased gap junctional intercellular communication among these cells [24]. Similarly, it has been reported that IL-1 $\beta$ enhances Cx43 expression in articular chondrocytes [25,26]. Further, the density of Cx43 positive cells is markedly enhanced in the superficial zone of osteoarthritic articular cartilage [8]. A more than 40fold increase in $\mathrm{Cx} 43$ protein expression was noted in the articular chondrocytes of OA cartilage compared to healthy controls, with the biggest differences in $\mathrm{Cx} 43$ accumulation in the superficial and mid zone of the articular cartilage [13]. High levels of Cx43 staining were seen early in OA and was noted in areas of healthy as well as degraded cartilage, suggesting that altered $\mathrm{Cx} 43$ expression may be an early phenotypic change in these cells prior to OA-associated cartilage destruction [13]. However, the mechanism of $\mathrm{Cx} 43$ upregulation in OA and the consequence of enhanced Cx43 expression in these cells within the osteoarthritic joint are not yet known. Among osteoblasts, we and others have shown that $\mathrm{Cx} 43$ impacts the expression of numerous genes by modulating several signal transduction cascades $[21,27,28]$. In the present study, we examine how increasing Cx43 levels in human and rabbit synovial fibroblasts affect the expression of several OA-associated catabolic and inflammatory genes.

\section{Methods}

\section{Cell culture and transfection}

The HIG82 rabbit synovial fibroblast-like cell line (ATCC) was cultured as described previously [24]. The SW982 human synovial sarcoma cell line (ATCC) was cultured in Leibovitz's L-15 medium and maintained in a $37^{\circ} \mathrm{C}$ incubator with atmospheric $\mathrm{CO}_{2}$. HIG82 cells were transfected with Lipofectamine 2000 (Life Technologies), as we have published [24]. SW982 cells were transfected with calcium phosphate co-precipitation, as described [29] or with Lipofectamine 2000. The pSFFV-Cx43 construct, which contains the full-length rat $\mathrm{Cx} 43$ open reading frame cloned into the EcoR1 site of the pSFFV-neo plasmid [30], was provided by Dr. Thomas Steinberg (Washington University, St Louis, MO). The pSFFV-neo empty vector [31] was provided by Dr. Gabriel Nunez (University of Michigan, Ann Arbor, MI). All plasmid DNA was prepared using PureYield endotoxin free plasmid maxi prep kit (Promega). Non-targeting and human GJA1 targeting-siRNA Smartpool constructs were purchased from Dharmacon and were used at $25 \mathrm{pmol} / \mathrm{cm}^{2}$. MG132, dissolved in DMSO, was used at $50 \mu \mathrm{M}$. The IKK-2 inhibitor IV (5-( $p$-Fluorophenyl)-2-ureido] thiophene-3carboxamide) was dissolved in DMSO and used at $10 \mu \mathrm{M}$. 
Cells were treated with MG132, IKK-2 inhibitor IV or DMSO as a vehicle control for 4-5 hours (real time PCR) or 1 hour (immunoblots) prior to harvest. IL-1 $\beta$ was used at $100 \mathrm{ng} / \mathrm{ml}$ for 20 minutes to stimulate the phosphorylation of the p65 subunit of NFkB, following pretreatment of the cells with MG132 inhibitor or DMSO control.

\section{RNA isolation and quantitative RT-PCR}

Forty-eight hours post transfection, cells were harvested for RNA extraction using Directzol RNA miniprep (Zymo). RNA $(1 \mu \mathrm{g})$ was reverse transcribed with either iScript (BioRad) or RevertAid (Fermentas) reverse transcription master mix, according to the manufacturers directions. Quantitative real time PCR was carried out using the SYBR green method, as described previously [24]. For rabbit synovial cell samples, relative gene expression was normalized to 18SrRNA data. For human synovial cell samples, the relative gene expression was simultaneously normalized to the expression of three house keeping genes, RPL13, HPRT and GAPDH using the GeNorm v3.5 Software (Ghent University Hospital Ghent, Belgium), as described previously [32]. All data were also normalized to the expression levels in the empty vector control. The primer sets used for PCR are shown in Table 1.

\section{MMP activity assay}

MMP activity was measured in conditioned media collected from cultured cells 72 hours post-transfection, using the EnzChek Gelatinase/Collagenase Assay kit (Life Technologies), according to manufacturer's directions. Briefly, conditioned media (100 $\mu \mathrm{l})$ was added to the fluorescently tagged gelatin substrate $(100 \mu \mathrm{l}, 100 \mu \mathrm{g} / \mathrm{ml}$ final concentration in the supplied $1 \mathrm{X}$ reaction buffer). The samples were incubated at room temperature for $2-4$ hours and at room temperature, followed by analysis of fluorescent intensity (excitation, $495 \mathrm{~nm}$, emission $515 \mathrm{~nm}$ ) on a fluorescent microplate reader. Data are displayed relative to the empty vector transfected control.

\section{Western blotting}

Western blotting of whole cell extracts isolated from cells in culture was done as previously described [33]. Briefly, whole cell extracts were prepared from cultured cells 72 hours post transfection using a modified RIPA buffer containing $50 \mathrm{mM}$ Tris, $\mathrm{pH} 8.0,150 \mathrm{mM} \mathrm{NaCl}$. $10 \mathrm{mM}$ sodium pyrophosphate, $10 \mathrm{mM}$ sodium fluoride, $10 \mathrm{mM} \beta$-glycerophosphate, $1 \mathrm{mM}$ EGTA, $1 \mathrm{mM}$ EDTA, $1 \%$ NP- $40,0.5 \%$ sodium deoxycholate, $0.1 \%$ SDS, and $1 \mathrm{X}$ HALT protease and phosphatase inhibitor cocktail (Thermo Scientific). Insoluble material was pelleted, and equal concentrations of the supernatants were electrophoresed on 10\% SDS-PAGE gels and transferred to

Table 1 PCR primers

\begin{tabular}{|c|c|c|c|}
\hline Target & Species & Primer 1 & Primer 2 \\
\hline MMP1 & Human & TIT GAT GGA CCT GGA GGA AAT C & TGA GCA TCC CCT CCA ATA CC \\
\hline MMP13 & Human & ATT AAG GAG CAT GGC GAC TTC T & CCC AGG AGG AAA AGC ATG AG \\
\hline ADAMTS4 & Human & CTA TGG GCA CTG TCT CTT AGA CAA AC & CAC TGG CGG TCA GCA TCA \\
\hline ADAMTS5 & Human & AAT AAC CCT GCT CCC AGA AAC A & GCG GTA GAT GGC CCT CTT C \\
\hline IL1 & Human & CGA ATC TCC GAC CAC CAC TAC & TCC ATG GCC ACA ACA ACT GA \\
\hline IL6 & Human & TGT AGC CGC CCC ACA CA & GGA TGT ACC GAA TTT GTT TGT CAA \\
\hline PTSG2 & Human & CAG CAC TTC ACG CAT CAG TाT T & CCA GCC CGT TGG TGA AAG \\
\hline HPRT & Human & TGA CAC TGG CAA AAC AAT GCA & GCT TGC GAC CTT GAC CAT CT \\
\hline GAPDH & Human & CCC ACT CCT CCA CCT TTG AC & CAT ACC AGG AAA TGA GCT TGA CAA \\
\hline RPL13 & Human & AGC CTT CGC TAG TCT CCG TAT G & TGG CTC TIT TTG CCC GTA TG \\
\hline Gjal & Rat & CGA TाT CCC CGA CGA CAA & TGG CTA ATG GCT GGA GTT CAT \\
\hline MMP1 & Rabbit & TGT ATC GTG TTG CAG CTC ATG A & AAA GCC CCA ATA TCA GTA GAA TGG \\
\hline MMP13 & Rabbit & AGT AGT TCC AAA GGC TAC AAC TTG TIT & GGA GTG GTC AAG CCC TAA GGA \\
\hline ADAMTS4 & Rabbit & ACT GGG TTC CGC GCT ACA & CCT GGC AGG TGA GTT TGC A \\
\hline ADAMTS5 & Rabbit & CCT GGG CCC CGA AGA AC & CGA ACG TCA AGT TGC ATT GC \\
\hline ILIB & Rabbit & TCC AGA CGA GGG CAT CCA & TGC CGG AAG CTC TTG TTG TA \\
\hline IL6 & Rabbit & GAA CCT GCA GCA GAA AAA CCA & GGC CGC GCA GGA TGA \\
\hline PTSG2 & Rabbit & GCT GTG GGC CAG GAA GTG & GCC AGA TTG TGG CAT ACA TCA \\
\hline 18SrRNA & multi & CAT TAA ATC AGT TAT GGT TCC TाT GG & TCG GCA TGT ATT AGC TCT AGA ATT AC \\
\hline
\end{tabular}


polyvinylidene difluoride membranes. Membranes were blocked in 5\% non- fat dry milk, probed with the indicated primary antibodies overnight, and detected with the appropriate horseradish peroxidase-conjugated antibodies and enhanced chemiluminescence detection reagents (BioRad). Blots were acquired and analyzed using an EpiChem gel documentation system (UVP Bioimaging Systems). The rabbit anti-connexin43 antibody was purchased from Sigma. The rabbit anti-phospho-NFkB p65 (Ser536) was purchased from Cell Signaling Technology. The mouse anti-GAPDH antibody was purchased from Millipore. Relative expression was calculated using ImageJ to quantitate band intensity. Data are relative to the expression of GAPDH.

\section{Statistical analysis}

Experiments were repeated a minimum of 3 times with triplicate wells, unless indicated otherwise. Graphs show averages with error bars indicating standard deviations. Samples were compared by an ANOVA for unpaired samples with a Dunnet's post-hoc test or a t-test, as appropriate, using Prism 6 software. A p-value $<0.05$ was used as a threshold for statistical significance.

\section{Results}

Quantitative real time RT-PCR showed that transient transfection with rat $\mathrm{Cx} 43$ (pSFFV-rCx43) in rabbit synovial fibroblasts (HIG82 cells) was sufficient to induce the gene expression of several catabolic factors associated with OA, including the matrix metalloproteinases, $M M P 1$ and $M M P 13$, and the aggrecanases, ADAMTS4 and ADAMTS5, compared to cells transfected with an empty vector (pSFFV-neo) (Figure 1A-B). The expression of these factors dose-dependently increased with the levels of the rat Gja1 (Cx43) transgene expression. Further, transfection with a Cx43 expressing plasmid in HIG82 cells increased matrix metalloproteinase activity in the conditioned media of these rabbit synovial cells as determined by a fluorometric MMP activity assay (Figure 1C). Similarly, transfection with $\mathrm{Cx} 43$ dose-dependently increased the gene expression of the OA-associated inflammatory mediators, IL1B, IL6 and PTGS2 (COX2) in HIG82 cells (Figure 2).

Next, we wanted to show that disruption of $\mathrm{Cx} 43$ expression or function would reduce expression of these genes. However, attempts to knockdown Cx43 expression with siRNAs were unsuccessful in these rabbit synovial cells. Meanwhile, pharmacologic inhibition of gap junction

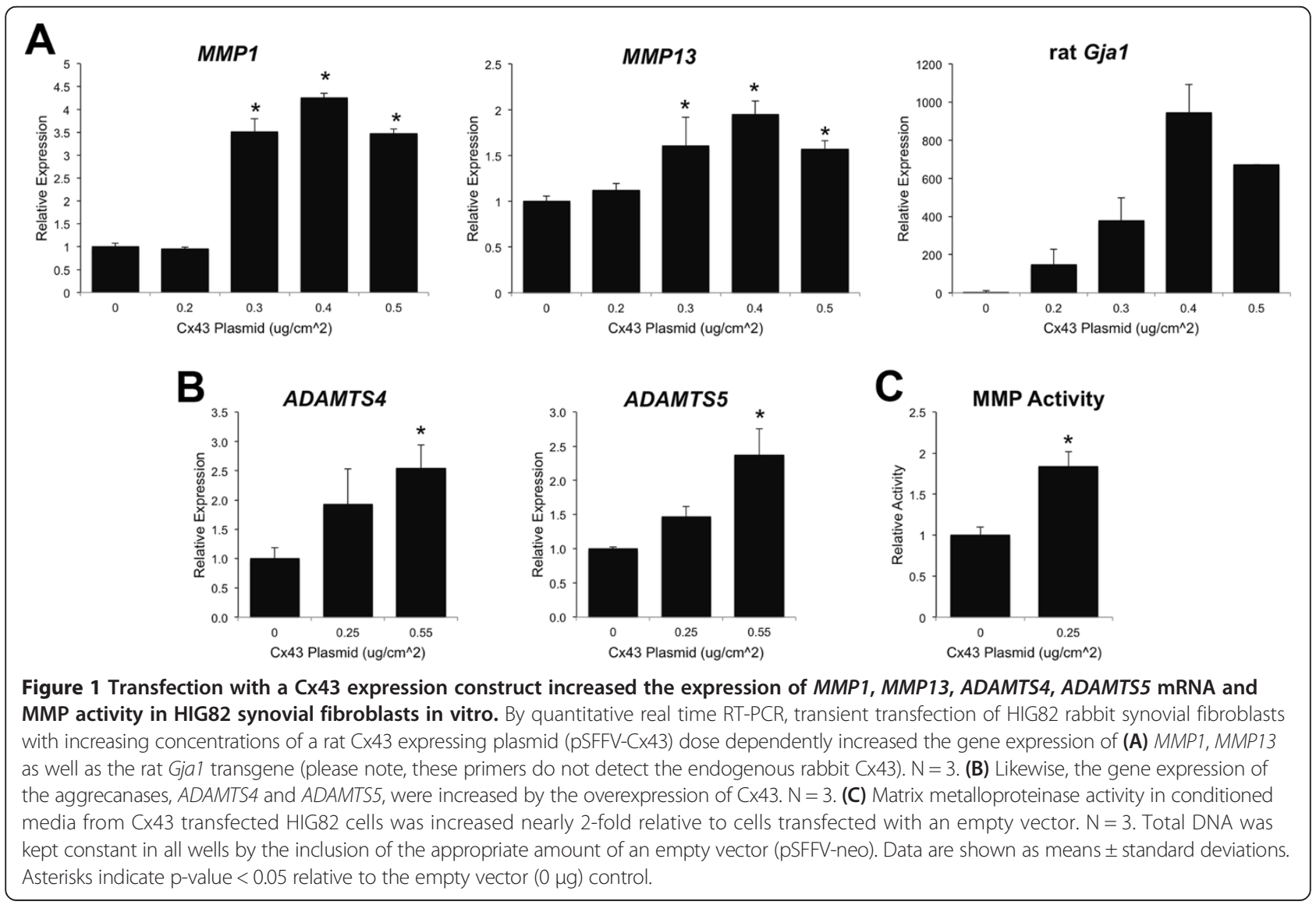




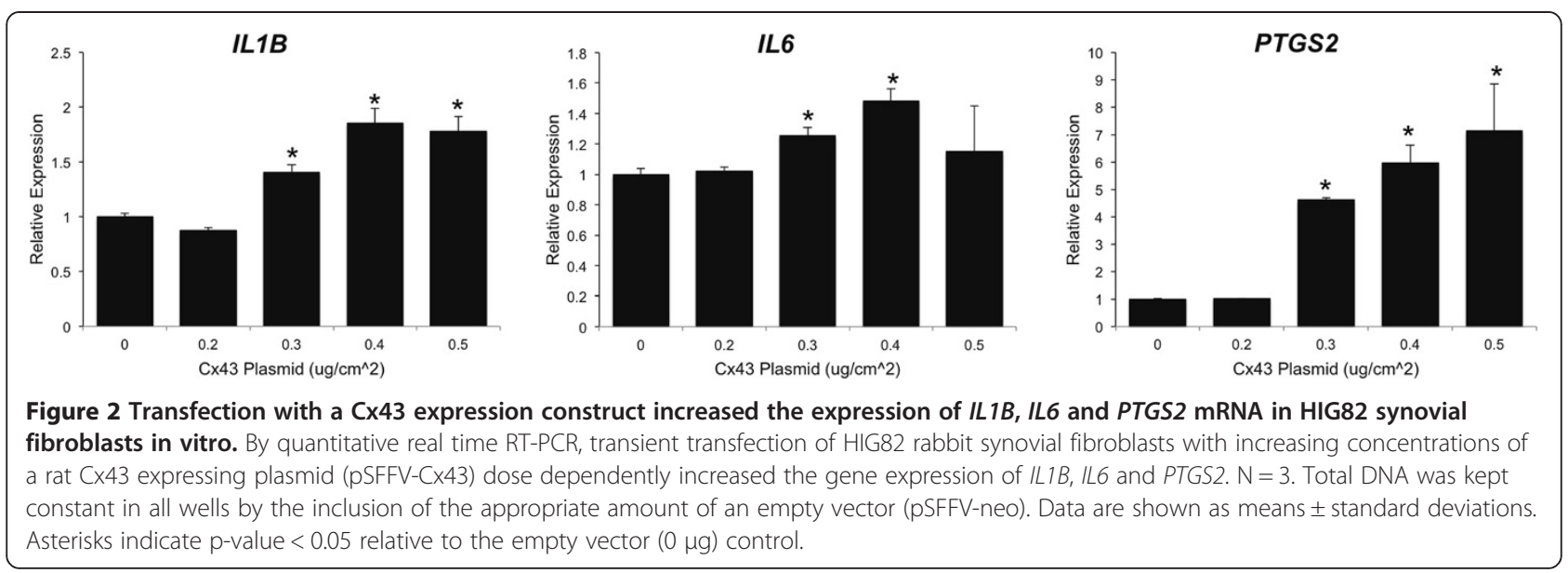

function with carbenoxolone or heptanol was effective at reducing gene expression and matrix metalloproteinase production in HIG82 cells, but issues of cell viability/cell health in the presence of these inhibitors made interpretation difficult (data not shown). As a result, we instead examined the effects of Cx43 on the function of human synovial fibroblast cell line (SW982) in which we could effectively knockdown Cx43 gene expression with commercial siRNAs. SW982 cells are derived from a human synovial sarcoma and behave similarly to human synovial fibroblasts including their ability to produce inflammatory and catabolic factors, including IL-1, IL-6, Cox2/PTGS2, iNOS/NOS2, TGF 3 , MMP-1, $-2,-3$ and -13 and ADAMTS-4, both basally and at markedly increased levels following treatment with IL-1 $\beta[34,35]$.

As was noted for HIG82 cells, increasing $\mathrm{Cx} 43$ protein expression (Cx43 protein levels were typically 1.5-2.5 fold higher than empty vector transfected controls as

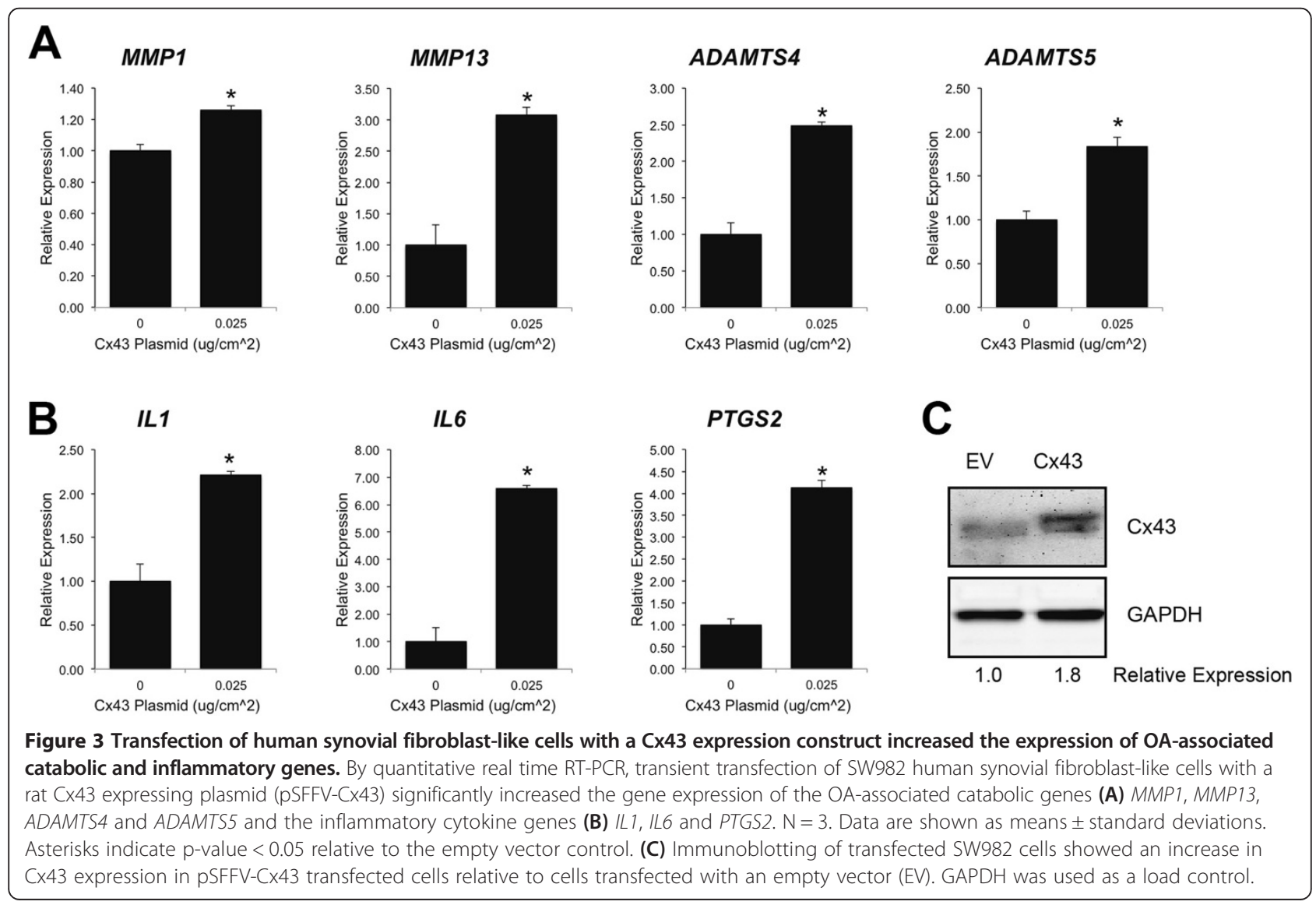




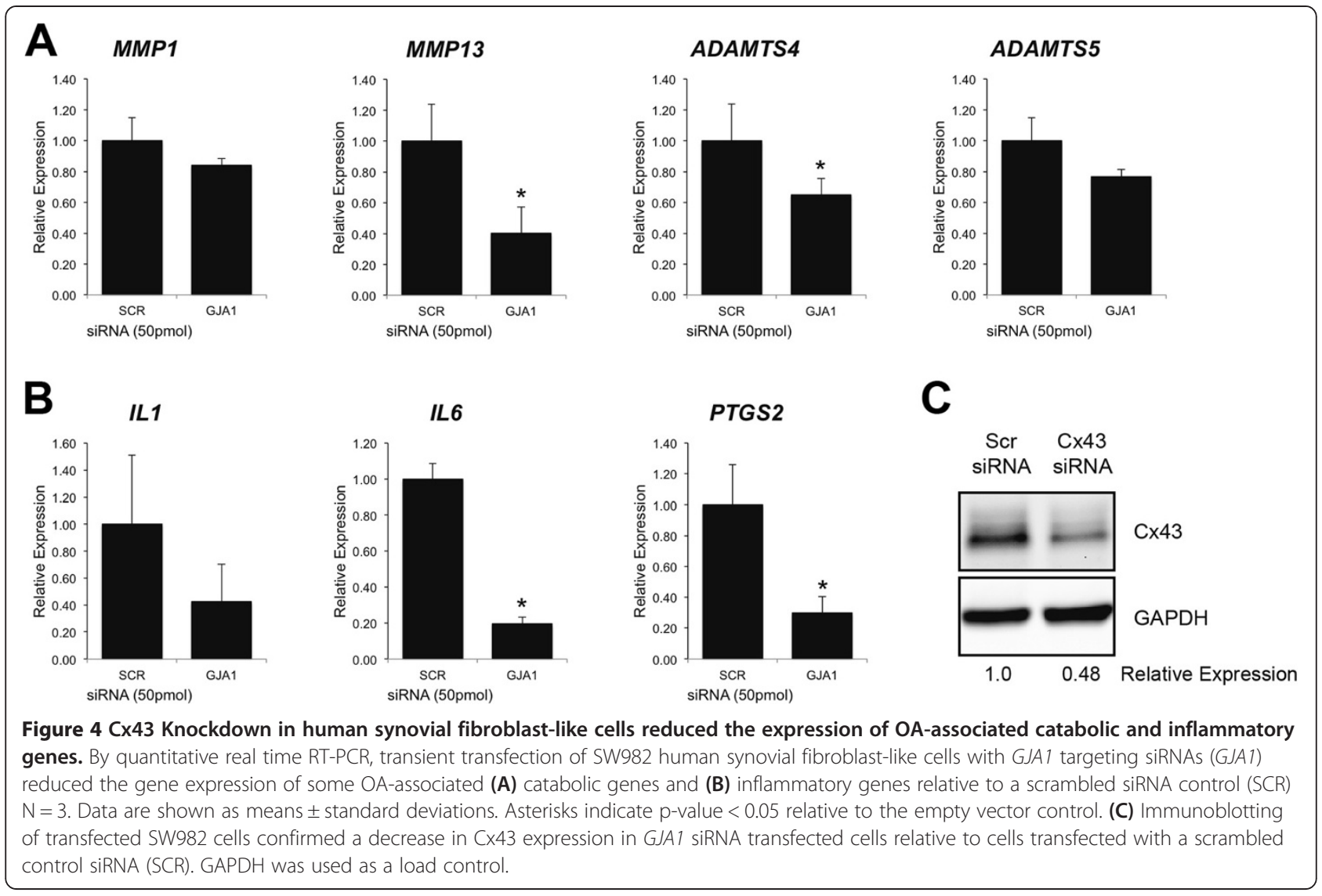

determined by western blotting) in SW982 human synovial cells by transient transfection enhanced the gene expression of MMP1, MMP13, ADAMTS4, ADAMTS5, IL1, IL6 and PTGS2 compared to cells transfected with an empty vector (Figure 3). Conversely, when Cx43 expression was knocked down in SW982 cells with siRNA directed against GJA1 (the gene encoding Cx43), the gene expression of MMP13, ADAMTS4, IL6 and PTGS2 were significantly reduced relative to cells transfected with a scrambled siRNA control (Figure 4A). The gene expression of MMP1, ADAMTS5 and IL1 were also mildly reduced but did not reach statistical significance.
Next, we examined the underlying molecular mechanisms by which Cx43 may impact expression of the genes. Because many of the Cx43-sensitive genes that we tested are direct targets of the canonical NFKB cascade, we evaluated the influence of $\mathrm{Cx} 43$ on this pathway. Examination of the phosphorylation of the p65 subunit of $\mathrm{NFkB}$ by western blotting revealed that increasing $\mathrm{C} \times 43$ expression enhanced phospho-p65 levels, while Cx43 knockdown diminished phospho-p65 levels (Figure 5). Importantly, inhibition of the NFkB pathway with MG132 blocked the impact of $\mathrm{Cx} 43$ overexpression on the production of a subset of these OA-associated catabolic and inflammatory
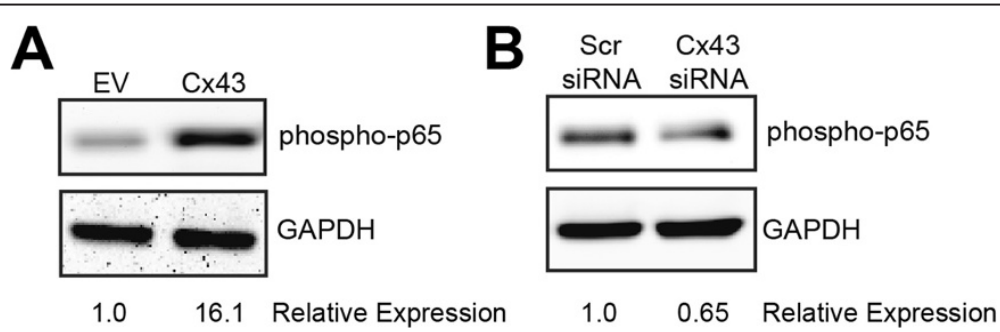

Figure 5 Modulation of Cx43 expression affected the NFKB pathway. Immunoblots from whole cell extracts of transiently transfected SW982 cells showed that (A) overexpression of Cx43 enhanced the abundance of phospho-p65 (RelA) subunit of the NFkB complex while (B) knockdown of Cx43 expression had the opposing effect. GAPDH was used as a load control. 


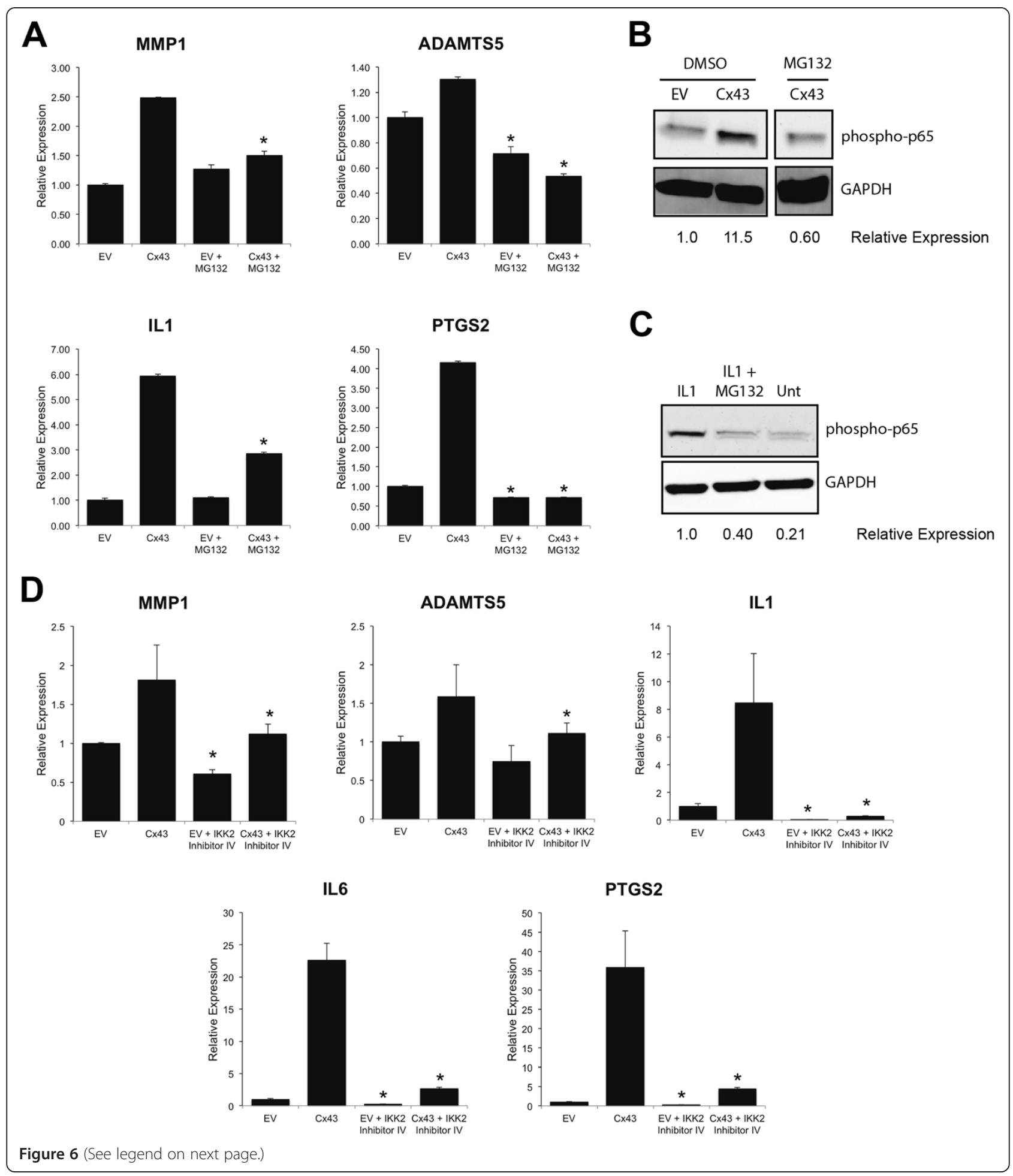


(See figure on previous page.)

Figure 6 Inhibition of the NFKB pathway prevented the ability of Cx43 overexpression to enhance the expression of some OA-associated catabolic and inflammatory genes. By quantitative real time RT-PCR, transient transfection of SW982 human synovial fibroblast-like cells with a rat CX43 expressing plasmid (pSFFV-Cx43) significantly increased the gene expression of the OA-associated catabolic and inflammatory genes (A) MMP1, ADAMTS5, IL1 and PTGS2. This effect of CX43 on the expression of these genes was abrogated by inhibition of the NFKB pathway with MG132 (50 $\mu$ M, 5 hours). $\mathrm{N}=3$. Data are shown as means \pm standard deviations. Asterisks indicate $\mathrm{p}$-value $<0.05$ relative to the corresponding vehicle treated control. (B) Immunoblots showed that Cx43 overexpression increased the abundance of phospho-p65 NFkB, an effect that could be inhibited by exposure to MG132 (50 $\mu \mathrm{M}, 1$ hours). GAPDH was used as a load control. This blot is from a single gel and single exposure but is from non-contiguous lanes. The irrelevant lanes have been digitally removed. (C) Immunoblot with anti-phospho-p65 NFkB antibodies confirms the effectiveness of MG132 to inhibit the NFKB pathway when the pathway is stimulated by IL1ß (100 ng/ml, 20 minutes). (D) Treatment with the NFkB pathway inhibitor (IKK2-inhibitor IV, $10 \mu \mathrm{M}, 4$ hours) reduced the Cx43-dependent expression of several OA-associated genes, as determined by quantitative real time RT-PCR. $N=3$. Data are shown as means \pm standard deviations. Asterisks indicate $\mathrm{p}$-value $<0.05$ relative to the corresponding vehicle treated control. genes, including MMP1, ADAMTS5, IL1 and PTGS2 and reduced the amount of phospho-p65 in Cx43-expressing SW982 cells (Figure 6A-C). Similarly, use of the NFkB pathway inhibitor, IKK-2 inhibitor IV, blocked the effects of Cx43 overexpression of several OA-associated genes (Figure 6D).

\section{Discussion}

In this manuscript, we showed that increasing Cx43 levels in synovial cells is sufficient to enhance the expression of OA-associated catabolic and inflammatory genes in both rabbit and human synovial fibroblasts. Given that $\mathrm{Cx} 43$ is upregulated in both articular chondrocytes and synovial cells in OA $[13,22]$, as well as the present data and the data of others suggesting that $\mathrm{Cx} 43$ can influence the expression of genes associated with OA $[22,23]$, it is important to consider that $\mathrm{Cx} 43$ could contribute to the subsequent pathology of the joint and may be a therapeutic target to treat OA. Of course, it must be acknowledged that this work is done in cell lines and needs to be confirmed in vivo. Promisingly, in a rat model of collagen induced rheumatoid arthritis, silencing Cx43 expression with siRNA diminished both inflammation and ankle joint destruction [36]. In addition, ex vivo Cx43 siRNA reduced the expression of inflammatory cytokines in rat fibroblast-like synovial cells from these animals [36]. These findings are consistent with our data, which also show that knockdown of $\mathrm{Cx} 43$ can reduce the expression of a subset of OA-associated catabolic genes and inflammatory genes. In fact, in our systems all of the tested OA-associated genes were diminished by transfection of the cells with GJA1-targeted siRNAs, even if only a subset reached statistical significance. Importantly, our model of $\mathrm{Cx} 43$ overexpression consistently produces a 1.5-2 fold increase in $\mathrm{Cx} 43$ protein in the human synoviocytes. This is consistent with the level of expression observed in synovial biopsies from OA patients relative to non-OA patients [22] and substantially less than the $\sim 30$-fold increase in Cx43 protein observed in articular chondrocytes from patients with OA [13].
Little is known regarding the molecular mechanisms by which alterations of $\mathrm{Cx} 43$ could affect gene expression in synovial cells. Our previous work in bone cells has shown that numerous signal transduction cascades, such as ERK and Protein Kinase C delta (PKC $)$, can influence gene expression downstream of $\mathrm{Cx} 43$ [32,33,37]. Others have shown in bone cells that $\mathrm{Cx} 43$ can regulate other pathways, including $\beta$-catenin expression $[38,39]$ and $\beta$ arrestin/cAMP signaling [40]. Less is known regarding the role of Cx43 and downstream signaling in the synovium or articular cartilage, beyond the propagation of $\mathrm{Ca}^{2+}$ waves $[41,42]$. In the present study, we showed that $\mathrm{Cx} 43$ regulates the NFKB signaling pathway in synovial fibroblasts, with gain of $\mathrm{Cx} 43$ increasing and loss of $\mathrm{Cx} 43$ decreasing signaling through this pathway. It is not surprising that $\mathrm{NF}_{\kappa} \mathrm{B}$ is a target influencing the expression of a subset of these OA-associated genes, as this pathway is intimately associated with OA and has been a target of therapeutic intervention in arthritic disease $[43,44]$. Rather, what is novel is that this is the first study that we are aware of that shows that $\mathrm{Cx} 43$ regulated the expression of OAassociated genes and the activity of the NFKB pathway. Our western blotting data clearly showed modulation of phosphorylation of p65 RelA as a result of increasing or decreasing $\mathrm{Cx} 43$ in these cells. Further, two pharmacologic inhibitors of the NFKB pathway markedly reduced the effect of $\mathrm{Cx} 43$ on gene expression. Of course, studying $\mathrm{NF} \mathrm{KB}$ pathway signaling in the context of a synovial sarcoma cell line (SW982) is a limitation as altered NFKB signaling is a hallmark of these cells. However, we have observed a similar regulation of $N F k B$ signaling by $\mathrm{Cx} 43$ in other cell types as well (data not shown). Even if these synovial sarcoma cells have elevated basal $\mathrm{NF}_{\mathrm{K} B}$, there is little reason to suspect that the mechanisms by which $\mathrm{Cx} 43$ modulates this pathway are not conserved among primary cells. Nonetheless, future experiments will examine the regulation of these synovial cell function in primary cells in culture or in vivo. Importantly, as has been observed in osteoblasts and osteocytes, it is unlikely that $\mathrm{NF}_{\kappa} \mathrm{B}$ is the only signaling pathway affected downstream of Cx43 in synovial cells. 
Indeed, Cx43 interacts with numerous signaling molecules and can affect signaling by modulating cell-to-cell diffusion of second messengers, as well as by structural interactions [21,45-47]. Future studies will look at signal transduction cascades such as PKC $\delta$, which is involved in Cx43-dependent signaling in bone cells where it converges on Runx2 [48] and has also been implicated in OA pathogenesis and the expression of $M M P 13$ via Runx2 [49,50].

Importantly, we do not know if this same Cx43dependent effect is also present in articular chondrocytes. While numerous studies have shown that $\mathrm{Cx} 43$ is expressed in articular chondrocytes, how Cx43 functions in these cells is uncertain. Cx43 can function as unopposed hemichannels in articular cartilage $[8,51,52]$, and the mechanisms that govern signal transduction in the context of classic cell-to-cell communication through gap junctions are likely different than with hemichannels [53]. In addition, studies have shown functional cell-tocell communication via classic gap junctions between articular chondrocytes in the superficial layer, as well as extensive gap junctional coupling among articular chondrocytes in a network that is analogous to the osteocytic canalicular network found in bone [13-15]. Future studies will investigate the role of $\mathrm{Cx} 43$ in articular chondrocyte function.

Interestingly, this is the first study to show that $\mathrm{Cx} 43$ abundance can impact the expression of PTGS2, the gene encoding COX2, an enzyme involved in the production of $\mathrm{PGE}_{2}$. Studies have shown a relationship between $\mathrm{Cx} 43$ and $\mathrm{PGE}_{2}$, particularly in response to mechanical load in osteocytes and articular chondrocytes, with mechanical stimulation increasing Cx43 expression and subsequently $\mathrm{PGE}_{2}$ release $[52,54,55]$. Those studies have focused to some extent on the $\mathrm{Cx} 43$-dependent release of $\mathrm{PGE}_{2}$ from cells. If $\mathrm{Cx} 43$ can also influence the transcription of PTGS2 and the synthesis of $\mathrm{PGE}_{2}$ in those systems, as it does in synovial cells, it should also be considered that the increase in $\mathrm{PGE}_{2}$ observed in osteocytes and articular chondrocytes following mechanical stimulation may be secondary to or in addition to the transcriptional control of PTGS2 by Cx43. Future studies will need to clarify this issue.

Combined with our previous work and the work of others showing increases in $\mathrm{Cx} 43$ in synovial cells the OA joint, the present data support a model in which OA-associated changes in the joint (e.g., inflammation, altered mechanical load) can increase $\mathrm{Cx} 43$ expression. Further, $\mathrm{Cx} 43$ upregulation is sufficient to lead to the production of additional catabolic and inflammatory factors. The result is a vicious cycle that culminates in joint destruction. Accordingly, it is reasonable to predict that targeting $\mathrm{Cx} 43$ or at least the subset of signal transduction cascades affected by $\mathrm{Cx} 43$ abundance could offer therapeutic benefit in the treatment of OA.

\section{Conclusions}

Increased levels of $\mathrm{Cx} 43$ are observed in synovial biopsies from patients with OA. Accordingly, we examined the impact of increased $\mathrm{Cx} 43$ on the expression of OAassociated genes. Increasing the levels of $\mathrm{Cx} 43$ is sufficient to drive the expression of catabolic and inflammatory genes by synovial cells, while knockdown of $\mathrm{Cx} 43$ could decrease the expression of these genes. The NFkB cascade mediates the effect of $\mathrm{Cx} 43$ on the expression of a subset of these OA-associated genes. As such, targeting Cx43 expression or function may be a viable therapeutic strategy to attenuate the catabolic and inflammatory environment of the joint during OA.

\section{Abbreviations}

ADAMTS4: Aggrecanase-1; ADAMTS5: Aggrecanase-2; Cx43: Connexin43;

IL: Interleukin; MMP: Matrix metalloproteinase; OA: Osteoarthritis; RT-PCR: Reverse transcription-polymerase chain reaction..

\section{Competing interests}

The authors declare that they have no competing interests.

\section{Authors' contributions}

$C N, A M B$ and $A G$ were involved in study design, data acquisition and interpretation and drafting of the manuscript. ERE and RJC were involved in data acquisition. JPS was involved in study design, interpretation of the data and drafting of the manuscript. All authors read and approved the final manuscript.

\section{Acknowledgements}

This work was supported by grants from the NIH/NIAMS (JPS: R01 AR063631 and R01 AR052719; AMB: F31 AR064673), Maryland Stem Cell Research Fund (2012-MSCRFE-0154) and the University of Maryland Short-term Research Training Program (SRTP) for Medical Students (RJC).

Received: 23 September 2014 Accepted: 25 November 2014 Published: 11 December 2014

\section{References}

1. Loeser RF, Goldring SR, Scanzello CR, Goldring MB: Osteoarthritis: a disease of the joint as an organ. Arthritis Rheum 2012, 64(6):1697-1707.

2. Benito MJ, Veale DJ, FitzGerald O, van den Berg WB, Bresnihan B: Synovial tissue inflammation in early and late osteoarthritis. Ann Rheum Dis 2005, 64(9):1263-1267.

3. van den Berg WB: The role of cytokines and growth factors in cartilage destruction in osteoarthritis and rheumatoid arthritis. Z Rheumatol 1999, 58(3):136-141.

4. Chevalier $X$ : Upregulation of enzymatic activity by interleukin-1 in osteoarthritis. Biomed Pharmacother 1997, 51(2):58-62.

5. Pelletier JP, Martel-Pelletier J, Abramson SB: Osteoarthritis, an inflammatory disease: potential implication for the selection of new therapeutic targets. Arthritis Rheum 2001, 44(6):1237-1247.

6. Donahue HJ, Guilak F, Vander Molen MA, McLeod KJ, Rubin CT, Grande DA, Brink PR: Chondrocytes isolated from mature articular cartilage retain the capacity to form functional gap junctions. J Bone Miner Res 1995, 10(9):1359-1364.

7. Stains JP, Civitelli R: Gap junctions in skeletal development and function. Biochim Biophys Acta 2005, 1719(1-2):69-81.

8. Knight MM, McGlashan SR, Garcia M, Jensen CG, Poole CA: Articular chondrocytes express connexin 43 hemichannels and $\mathrm{P} 2$ receptors - a putative mechanoreceptor complex involving the primary cilium? J Anat 2009, 214(2):275-283. 
9. Chi SS, Rattner JB, Sciore P, Boorman R, Lo IK: Gap junctions of the medial collateral ligament: structure, distribution, associations and function. $J$ Anat 2005, 207(2):145-154.

10. Schwab W, Hofer A, Kasper M: Immunohistochemical distribution of connexin 43 in the cartilage of rats and mice. Histochem J 1998, 30(6):413-419.

11. Kolomytkin OV, Marino AA, Sadasivan KK, Meek WD, Wolf RE, Hall V, McCarthy KJ, Albright JA: Gap junctions in human synovial cells and tissue. J Cell Physiol 2000, 184(1):110-117.

12. Hellio Le Graverand MP, Sciore P, Eggerer J, Rattner JP, Vignon E, Barclay L, Hart DA, Rattner JB: Formation and phenotype of cell clusters in osteoarthritic meniscus. Arthritis Rheum 2001, 44(8):1808-1818.

13. Mayan MD, Carpintero-Fernandez P, Gago-Fuentes R, Martinez-de-llarduya $O$, Wang HZ, Valiunas V, Brink P, Blanco FJ: Human articular chondrocytes express multiple gap junction proteins: differential expression of connexins in normal and osteoarthritic cartilage. Am J Pathol 2013, 182(4):1337-1346.

14. Chi SS, Rattner JB, Matyas JR: Communication between paired chondrocytes in the superficial zone of articular cartilage. J Anat 2004, 205(5):363-370.

15. Mayan MD, Gago-Fuentes R, Carpintero-Fernandez P, Fernandez-Puente P, Filgueira-Fernandez P, Goyanes N, Valiunas V, Brink PR, Goldberg GS, Blanco FJ: Articular chondrocyte network mediated by gap junctions: role in metabolic cartilage homeostasis. Ann Rheum Dis 2013, [Epub ahead of print]

16. Spray DC, Ye ZC, Ransom BR: Functional connexin "hemichannels": a critical appraisal. Glia 2006, 54(7):758-773

17. Saez JC, Retamal MA, Basilio D, Bukauskas FF, Bennett MV: Connexin-based gap junction hemichannels: gating mechanisms. Biochim Biophys Acta 2005, 1711(2):215-224

18. Kar R, Batra N, Riquelme MA, Jiang JX: Biological role of connexin intercellular channels and hemichannels. Arch Biochem Biophys 2012, 524(1):2-15.

19. Batra N, Kar R, Jiang JX: Gap junctions and hemichannels in signal transmission, function and development of bone. Biochim Biophys Acta 2012, 1818(8):1909-1918

20. Batra N, Burra S, Siller-Jackson AJ, Gu S, Xia X, Weber GF, DeSimone D, Bonewald LF, Lafer EM, Sprague E, Schwartz MA, Jiang JX: Mechanical stress-activated integrin alpha5beta1 induces opening of connexin 43 hemichannels. Proc Nat Acad Sci U S A 2012, 109(9):3359-3364.

21. Buo AM, Stains JP: Gap junctional regulation of signal transduction in bone cells. FEBS Lett 2014, 588(8):1315-1321.

22. Marino AA, Waddell DD, Kolomytkin OV, Meek WD, Wolf R, Sadasivan KK Albright JA: Increased intercellular communication through gap junctions may contribute to progression of osteoarthritis. Clin Orthop Relat Res 2004, 422:224-232

23. Kolomytkin OV, Marino AA, Waddell DD, Mathis JM, Wolf RE, Sadasivan KK Albright JA: IL-1beta-induced production of metalloproteinases by synovial cells depends on gap junction conductance. Am J Physiol Cell Physiol 2002, 282(6):C1254-C1260.

24. Niger C, Howell FD, Stains JP: Interleukin-1 beta increases gap junctional communication among synovial fibroblasts via the extracellular-signalregulated kinase pathway. Biol Cell 2010, 102(1):37-49.

25. Tonon R, D'Andrea P: The functional expression of connexin 43 in articular chondrocytes is increased by interleukin 1beta: evidence for a Ca2 + -dependent mechanism. Biorheology 2002, 39(1-2):153-160.

26. Tonon R, D'Andrea P: Interleukin-1 beta increases the functional expression of connexin 43 in articular chondrocytes: evidence for a Ca2 +-dependent mechanism. J Bone Miner Res 2000, 15(9):1669-1677.

27. Plotkin LI, Bellido T: Beyond gap junctions: connexin43 and bone cell signaling. Bone 2013, 52(1):157-166

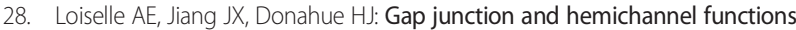
in osteocytes. Bone 2013, 54(2):205-212.

29. Jordan M, Schallhorn A, Wurm FM: Transfecting mammalian cells: optimization of critical parameters affecting calcium-phosphate precipitate formation Nucleic Acids Res 1996, 24(4):596-601.

30. Beyer EC, Paul DL, Goodenough DA: Connexin43: a protein from rat heart homologous to a gap junction protein from liver. J Cell Biol 1987, 105(6 Pt 1):2621-2629.

31. Fuhlbrigge RC, Fine SM, Unanue ER, Chaplin DD: Expression of membrane interleukin 1 by fibroblasts transfected with murine pro-interleukin 1 alpha cDNA. Proc Natl Acad Sci U S A 1988, 85(15):5649-5653.

32. Niger C, Luciotti MA, Buo AM, Hebert C, Ma V, Stains JP: The regulation of Runx2 by FGF2 and connexin 43 requires the inositol polyphosphate/protein kinase Cdelta cascade. J Bone Miner Res 2013, 28(6):1468-1477.
33. Niger C, Buo AM, Hebert C, Duggan BT, Williams MS, Stains JP: ERK acts in parallel to PKCdelta to mediate the connexin43-dependent potentiation of Runx2 activity by FGF2 in MC3T3 osteoblasts. Am J Physiol Cell Physiol 2012, 302(7):C1035-C1044.

34. Yamazaki T, Yokoyama T, Akatsu H, Tukiyama T, Tokiwa T: Phenotypic characterization of a human synovial sarcoma cell line, SW982, and its response to dexamethasone. In Vitro Cell Dev Biol Anim 2003, 39(8-9):337-339.

35. Kim KO, Park SY, Han CW, Chung HK, Yoo DH, Han JS: Effect of sildenafil citrate on interleukin-1beta-induced nitric oxide synthesis and iNOS expression in SW982 cells. Exp Mol Med 2008, 40(3):286-293.

36. Tsuchida S, Arai Y, Kishida T, Takahashi KA, Honjo K, Terauchi R, Inoue H, Oda R, Mazda O, Kubo T: Silencing the expression of connexin 43 decreases inflammation and joint destruction in experimental arthritis. J Orthop Res 2013, 31(4):525-530.

37. Hebert C, Stains JP: An intact connexin43 is required to enhance signaling and gene expression in osteoblast-like cells. J Cell Biochem 2013, 114(11):2542-2550

38. Loiselle AE, Lloyd SA, Paul EM, Lewis GS, Donahue HJ: Inhibition of GSK-3beta rescues the impairments in bone formation and mechanical properties associated with fracture healing in osteoblast selective connexin 43 deficient mice. PLoS One 2013, 8(11):e81399.

39. Bivi N, Pacheco-Costa R, Brun LR, Murphy TR, Farlow NR, Robling AG, Bellido T, Plotkin LI: Absence of Cx43 selectively from osteocytes enhances responsiveness to mechanical force in mice. J Orthop Res 2013, 31(7):1075-1081.

40. Bivi N, Lezcano V, Romanello M, Bellido T, Plotkin Ll: Connexin43 interacts with betaarrestin: a pre-requisite for osteoblast survival induced by parathyroid hormone. J Cell Biochem 2011, 112(10):2920-2930.

41. D'Andrea P, Calabrese A, Capozzi I, Grandolfo M, Tonon R, Vittur F: Intercellular $\mathrm{Ca} 2+$ waves in mechanically stimulated articular chondrocytes. Biorheology 2000, 37(1-2):75-83.

42. Grandolfo M, Calabrese A, D'Andrea P: Mechanism of mechanically induced intercellular calcium waves in rabbit articular chondrocytes and in HIG-82 synovial cells. J Bone Miner Res 1998, 13(3):443-453.

43. Roman-Blas JA, Jimenez SA: NF-kappaB as a potential therapeutic target in osteoarthritis and rheumatoid arthritis. Osteoarthritis Cartilage 2006, 14(9):839-848.

44. Marcu KB, Otero M, Olivotto E, Borzi RM, Goldring MB: NF-kappaB signaling: multiple angles to target OA. Curr Drug Targets 2010, 11(5):599-613.

45. Kameritsch P, Pogoda K, Pohl U: Channel-independent influence of connexin 43 on cell migration. Biochim Biophys Acta 2012, 1818(8):1993-2001.

46. Vinken M, Decrock E, Leybaert L, Bultynck G, Himpens B, Vanhaecke T, Rogiers $\mathrm{V}$ : Non-channel functions of connexins in cell growth and cell death. Biochim Biophys Acta 2012, 1818(8):2002-2008.

47. Herve JC, Derangeon M, Sarrouilhe D, Giepmans BN, Bourmeyster N: Gap junctional channels are parts of multiprotein complexes. Biochim Biophys Acta 2012, 1818(8):1844-1865.

48. Lima F, Niger C, Hebert C, Stains JP: Connexin43 potentiates osteoblast responsiveness to fibroblast growth factor 2 via a protein kinase C-delta/Runx2-dependent mechanism. Mol Biol Cell 2009, 20(11):2697-2708

49. Im HJ, Muddasani P, Natarajan V, Schmid TM, Block JA, Davis F, van Wijnen AJ, Loeser RF: Basic fibroblast growth factor stimulates matrix metalloproteinase-13 via the molecular cross-talk between the mitogenactivated protein kinases and protein kinase Cdelta pathways in human adult articular chondrocytes. J Biol Chem 2007, 282(15):11110-11121.

50. Wang X, Manner PA, Horner A, Shum L, Tuan RS, Nuckolls GH: Regulation of MMP-13 expression by RUNX2 and FGF2 in osteoarthritic cartilage. Osteoarthritis Cartilage 2004, 12(12):963-973

51. Garcia M, Knight MM: Cyclic loading opens hemichannels to release ATP as part of a chondrocyte mechanotransduction pathway. J Orthop Res 2010, 28(4):510-515.

52. Zhang J, Zhang H, Zhang M, Qiu Z, Wu Y, Callaway DA, Jiang JX, Lu L, Jing L, Yang T, Wang MQ: Connexin43 hemichannels mediate small molecule exchange between chondrocytes and matrix in biomechanically-stimulated temporomandibular joint cartilage. Osteoarthritis Cartilage 2014, 22(6):822-830

53. Plotkin Ll: Connexin 43 hemichannels and intracellular signaling in bone cells. Front Physiol 2014, 5:131. 
54. Siller-Jackson AJ, Burra S, Gu S, Xia X, Bonewald LF, Sprague E, Jiang JX: Adaptation of connexin 43-hemichannel prostaglandin release to mechanical loading. J Biol Chem 2008, 283(39):26374-26382.

55. Cherian PP, Siller-Jackson AJ, Gu S, Wang X, Bonewald LF, Sprague E, Jiang JX: Mechanical strain opens connexin 43 hemichannels in osteocytes: a novel mechanism for the release of prostaglandin. Mol Biol Cell 2005, 16(7):3100-3106

doi:10.1186/1471-2474-15-425

Cite this article as: Gupta et al:: Connexin43 enhances the expression of osteoarthritis-associated genes in synovial fibroblasts in culture. BMC Musculoskeletal Disorders 2014 15:425.

\section{Submit your next manuscript to BioMed Central and take full advantage of:}

- Convenient online submission

- Thorough peer review

- No space constraints or color figure charges

- Immediate publication on acceptance

- Inclusion in PubMed, CAS, Scopus and Google Scholar

- Research which is freely available for redistribution 